\title{
Canine embodiment in South African lyric poetry
}

\author{
Wendy Woodward \\ Wendy Woodward is Professor Emerita in the English Department at the University of the \\ Western Cape where she taught South African literature, animal studies and Creative \\ Writing. \\ Email: wendywoodward97@gmail.com
}

\section{Canine embodiment in South African lyric poetry}

This article discusses South African lyric poetry in English including translations since the 1960s. Rather than being private statements, South African lyrics, like all lyrics, are essentially dialogic-in relation to the philosophical, the political or the psychological. The poems examined here are in dialogue with dogs, their embodiment, their subjectivities, their contiguities with humans. This article considers how trans-species entanglements between human and canine, whether convivial or adversarial, manifest poetically in myriad ways in gendered and/or racialised contexts and analyses how the vulnerabilities of both humans and dogs are made to intersect. Ruth Miller portrays dogs as divine creations who are uncertain and "embarrassed". Ingrid Jonker's poems intertwine human and canine, foregrounding gendered vulnerabilities. Where dogs are figured metonymically, entanglements of human and dog break down binary categorisations, in Jonker's poems as well as in those of other poets. Mongane Wally Serote's creatural humans, for example, seem both animal and human. Oswald Mtshali figures dogs within apartheid structures as antagonists, protectors or savage scavengers. More recent poems, influenced perhaps by new thinking about the animal subject, imagine dogs in compassionate interspecies connections. Many of these recent elegiac poems, in particular those by Jenna Mervis and Harry Owen, are attentive to beloved dogs but without sentimentality or the imposition of an anthropocentric focus. Keywords: dogs; lyric poetry; South African poetry; trans-species.

\section{Introduction}

Dogs in South African lyric poetry in English are homely and unhomely, creatures of the day or beasts from our nightmares, domesticated or murderously feral. These dogs are protean-seemingly our creatures, but also themselves and other. We find ourselves tracking them in terrains we had never anticipated, 
following them into persuasive poems which draw us in and defamiliarise the usual, queering our expectations of dogs, encouraging us, as readers, to engage with them anew. They may pose against the yellow grass, undeniably a subject in our quest, or they may slip between acacias, mere shadows, their paw prints scuffed and faint, easily missed. On another expedition, prints in a semi-desert interweave almost indistinguishably with those of a human. One traumatic morning we see bloody signs of a human corpse on a rubbish dump, a baby's life extinguished by hungry dogs who live beyond civility. Dogs may be our shadows but they are also our familiars; in domestic situations they are often beloved, their bodies buried in gardens known to them, their deaths memorialised in heartfelt poems.

\section{Reading vulnerabilities}

How does South African poetry, or to be more specific for the purpose of this article, the South African lyric since the 1960s, imagine dog subjectivities as well as human-dog relationalities and their contradictions? Lyrics, traditionally, have been conceptualised as private often solitary utterances "by a single speaker, who expresses a state of mind or a process of perception, thought, and feeling" (Abrams and Harpham 210). Mara Scanlon suggests, instead, via Paul Celan, that all poetry, particularly the lyric, has an "inherent addressivity" (1), that it is dialogic and engaged, so much so that "the poem is based in a fundamental representation of, orientation toward, or response to otherness, as indicated by theorists such as Martin Buber or Emmanuel Levinas" (3). Scanlon also incorporates the potential of poetic devices to "encode or signal such otherness or exchange" (3). This is how I will read the poems-as dialogic where the dog's awareness either presents itself or merges with the voice of the human speaker, even as very specific socio-political discourses-of racialised politics, gender, madness-recur.

An essay on poetry and animals could not begin without recourse to Elizabeth Costello's lecture on "The Poets and the Animals" in J. M. Coetzee's The Lives of Animals (1999). Coetzee has Elizabeth Costello foreground the figuring of the animal's embodiment. She praises Ted Hughes for "bodying forth the jaguar" in his poem. Through "poetic invention" he "shows us how to bring the living body into being within ourselves" (53). Dismissing poetry in which animals feature only symbolically as stand-ins for "human qualities" (50), she prefers poetry which is "not about the animal but a record of an engagement with him" (51). These issues of reading and figuring are at the heart of a consideration of dogs in South African lyrics. At the same time, the "living body" of any dog in South African lyrics may be located within specific trans-species entanglements as well as within what Clare Jean Kim terms "the synergistic taxonomies of race and species" (18).

Tydskrif vir Letterkunde 55.3 (2018) 
Canine embodiment in South African lyric poetry

Ruth Miller's metaphysical poem "Dog" (1990) is not situated in a recognisable South Africa per se, but, although her dog is divinely pristine in his creation, he is substantially embodied. The lyric dialogues with the canine himself as well as with a quotation from Rainer Maria Rilke which serves as an epigraph: "... the point where it begins to be dog, the place in it where God ... would have sat down for a moment when the dog was finished, in order to watch it under the influence of its first embarrassments and inspirations" (Miller 54). The creation of the dog is an expansive moment; God does not claim dominion over this newly fashioned animal but pauses (presumably resting after creating others) to observe with fondness, even love, the dog's dawning moment of awareness of becoming-dog. The dog is depicted as highly sensitive, experiencing complex emotions which exceed mere sentience. The poem, in three stanzas, details the dog's response to being "[u]nder the influence of its first embarrassment" and then "under the influence of its first inspirations".

The speaker in the first stanza tentatively imagines the dog, embarrassed, vulnerable, newly embodied:

Was it shy of the wind which brought distinctive messages

Or startled at hint of subterranean passages

Jibbing perhaps at the smell of the suggestion

That there was chaos somewhere and congestion-(54-5)

The speaker's questions exemplify Elizabeth Costello's notion of the "sympathetic imagination" in which being able to "think ourselves into the being of another" is without boundaries (Coetzee 35). The dog's embarrassed sense of the world and of his being surpasses the figuring of animal consciousness as merely "kinetic" however, which is how Coetzee has Costello conceptualise animal awareness (51): the dog's responses to his potential fear of the undefined "chaos" and "congestion" are more complex. Miller has the dog respond via his primary sense, that of smell, which grounds him in relation to the undefined threats, and the stanza ends, reassuringly, even though still with a question:

Was his maker careful to fondle the frightened ears, the stirred pelt

When dog sensed that there were other dogs abroad-not only

God and himself? (55)

Here the dog shifts from "it" to a personal pronoun as though the dog is reduced to an "it" when he inhabits the Rilke discussion but graduates to a "he" when he is agentive. Again the dog's responses are embodied, by means of his "ears" and "pelt"- the latter a curious term to use for a lively dog, when the word generally connotes the skin and fur of a dead animal. Given the phrasing of the quoted rhetorical question it is to be expected that God meted out love for his creation, even as the dog identified seamlessly with God. The humour of the dog-god palindrome is revivified in the entirely understandable literal interpretation of the dog who believes himself and God to be the same, a surmise not undermined by

Tydskrif vir Letterkunde 55.3 (2018) 
the speaker, so that the sacredness of the dog is implicitly endorsed. In the second stanza the dog is inspired; he "discover[s] and create[s]":

A stick in his mouth, a stone in a pond, a feather

Becoming bone to be buried, splash to be harried and all the weather

Blowing on a blue day. (55)

The enjambed lines convey the hurtling joie de vivre of the dog, who, like an artist, is creative, transforming a feather into a "bone to be buried". The rhythm of these lines recalls accentual verse where "only the beat of the strong stresses counts in the scanning while the number of intervening light syllables is highly variable" (Abrams and Harpham 221-2). The alliteration further emphasises the beat especially in the last line quoted here. The onomatopoeia of "splash to be harried" conveys a wild imagination as the weather imitates the dog's frolicking. The poet is merely secondary, a reporter who "recreate[s]" the "imagery" of all these gloriously embodied activities. At the same time the dog is able to reason and is a repository of knowledge based on his olfactory sense which informs him of "deliciousness" emanating either from food or "a bitch in season". Rhyme and rhythm foster a dialogue with the dog subject's sensuality, with Miller's linguistic playfulness formally contained.

The final stanza of Miller's "Dog" returns to the opening supposition about canine creation, turning from the kinetic imagery to a more philosophical ending about "[ $t]$ he point where it begins to be dog". Still, the dog's embodied presence and awareness manifest strongly:

$[\ldots]$ neither dog nor god is interested in anything stronger

Or weaker than exactly where God decided to place his finger. (55)

An apostrophe, according to Tom Bristow, is a "turning away from the world to address an abstract idea” (4) yet Miller interweaves Rilke's philosophising with the affective figuring of an 'actual' dog in the world. On a par with "god" (a lesser divine?) the dog is in awe of God, the supreme creator. These creators are implicitly juxtaposed in dialogue: the poet, the dog and God. The poet, referred to here, who only "recreated [...] imagery", does not manifest in this entanglement which is a sacred, embodied one.

In Ingrid Jonker's poems considered below Costello's analysis of the separation of the symbolic from the embodied animal is contradicted when the figuring of a dog and the woman speaker slips between metonymy and embodiment. Both woman and dog are creatures of vulnerability depicted relationally. For philosopher Anat Pick, a "creaturely poetics" begins with the fragile nature of "the creature [who] is first and foremost a living body-material, temporal, and vulnerable" (5). Embodiment defines human and animal according to Pick and thus challenges the prejudices of speciesism and anthropocentrism by "provid[ing] a critical space for thinking of the human outside Cartesian abstractionism, as rig- 


\section{Canine embodiment in South African lyric poetry}

orously material" and by "mak[ing] for a different sort of aesthetics and ethics" with embodiment as the basis for analysis (6).

In an early poem, "Ontvlugting" (Escape), originally published in Jonker's first anthology Ontvlugting in 1956, which imagines her flight from Valkenberg, a psychiatric hospital in Cape Town, to Gordon's Bay, the speaker is painfully intermeshed with elements of nature, longing, paradoxically, for "fulfilment of my pain in you" (Jonker Black Butterflies 39). The addressee is ambiguous-either the elements of nature she identifies with or the other part of a couple implicit in "where we once did pass" (39). In this short poem of six couplets, the third couplet affirms in Afrikaans:

Ek is die hond wat op die strande draf en dom-allenig teen die aandwind blaf (n. p.)

André Brink and Antjie Krog translate these lines:

I am the dog that slinks from beach to beach

barks dumb-alone against the evening breeze. (Jonker Black Butterflies 39)

Jack Cope and William Plomer, in the second of their translations, prefer to sustain the rhyme in the couplets over the original meaning:

I am the dog that trots along the strand

and barks alone against the blowing sand. (Jonker Selected Poems Revised 11)

Although "slinks" in Brink and Krog's version changes the connotation of "draf" (trots), their rendering of "dom-allenig" as "dumb-alone" is macabrely appropriate. Michael Cope tells the "back-story" of a very specific dog on Clifton Fourth Beach where he lived as a child with his father, Jack Cope, and where Jonker was "a frequent visitor and sometimes resident" who would have known the dog's narrative (n. p.). This terrier's obsession with barking at the waves agitated the local residents and the dog's owner to such an extent that the dog's vocal cords were removed. Still, " $[\mathrm{t}]$ he dog carried on barking at its enemy, the wave, but now silently" (Cope n. p.). The sundering of the wholeness of the dog's body and the inconsequentiality of his silenced pursuit are conflated with the speaker's vulnerability in the quoted couplet. The poem ends with the tragically premonitory lines foreshadowing Jonker's suicide by drowning:

My body lies washed up in grass and wrack

Wherever memory should call us back. (Jonker Selected Poems Revised 11)

With "Escape" as a forerunner, Jonker's "Dog" reads as a profound meditation on trans-species interconnections between the body of a woman and the body of a dog in a dynamic dialogic encounter. The poem has a dog as the speaker yet a woman's voice resonates throughout the poem. The poem has been translated from the Afrikaans twice by Cope and Plomer (Jonker Selected Poems and Selected Poems Revised) as well as by Brink and Krog (Jonker Black Butterflies),

Tydskrif vir Letterkunde 55.3 (2018) 
but I will rely on the former's 1968 translation. The poem opens with a statement of obeisance, even masochism: "I lie under your hand-a cur" (42), the addressee being the "white master" of the penultimate line. Whiteness signifies terror for the speaker in relation both to the moon and to the "master," devoid of compassion. Cope and Plomer (Jonker Selected Poems Revised) and Brink and Krog (Jonker Black Butterflies) prefer the even more specific "white baas" with all its connotations of a South African white supremacy. The term intertwines gendered and racialised othering which are both to be mastered. The "cur" in stanza one is abject, cast out "in the snarling silence / in the whimpering moon" (emphasis added), the very landscape an extension of the fearful, kennelled dog who longs for liberation from the hand of the master in order to go "hunting hares / over my own karoo / over my burning plain / from ochre to ochre" (Jonker Selected Poems 42).

In contrast to the dog's desire for spaciousness, colour and even excessive heat, the "white plains of [the master's] hands!" (42) proffer only cold, moonlit sterility. In the final stanza the lines "with my teeth bared I shall / jerk to the sly rhythm of the moon" suggest not only a vulnerable aggression while pulling at a chain but possibly a sexual and hormonal response. Unusually, the trope of the moon does not provide succour for the feminine as the speaker longs for escape. That she will "listen to my sweetness and distance / my long-echoing bark / from my kennel" (42) does not suggest an actual liberation but an imagined one. The poem ends with an invocation to "white moon, white master / in the night" (42) yet neither heavenly body nor human provide succour or sanctuary for the dog / woman / racialised other-the moon is a trickster, the master an autocrat with empty hands, devoid of nurturance. The dog in this poem seems inextricably a human speaker and a canine one in a metonymic contiguity. In spite of, or maybe even because of this dog's dual import, Jonker's embodiment of the dog in her vulnerabilities, to borrow Costello's words, "return[s] the living, electric being to language" (Coetzee 65), in the poem's conflation of woman and animal. The woman is never dehumanised by this emphasis on her animality; instead the vulnerability of their entangled embodiment attests to a creaturely poetics.

In "Child of the Song" Mongane Wally Serote also conflates human and animal in a creaturely poetics but here embodied entanglement is playfully presented in a trans-species blurring. James Matthews, to whom the poem is dedicated, appears to be the addressee, affectionately admonished for passing time on music; and reminded about the need to remember the past, and the imperative to recall their bravery for "with song and dance we defied death". The poem begins as if in the middle of a conversation:

so you heard the night break into a laughter

when the dogs began to howl 
Canine embodiment in South African lyric poetry

and now you pass the day

having heard the scream of cats making love

The speaker tells the addressee that his "memory"

like your eyes

like your whiskers

was witness to it all

Now the addressee seems challenged by a hangover. His "memory", "eyes" and "whiskers" are referred to again with "whiskers [...] smell[ing] of alcohol". Whiskers could refer to a human's moustache but, given that dogs and cats have just appeared in the poem, the "whiskers" suggest the human's embodied animality which seems mundanely accepted rather than feted or denigrated. The poem ends powerfully, warning that "a fighter" should not waste time on park benches. In the light of this exhortation to a fighter in the anti-apartheid struggle, having animal characteristics could make him preternaturally aware of his environment of which he could seamlessly be a part.

Some of Oswald Joseph Mtshali's poems from Sounds of a Cowhide Drum (1971) embellish and extend trans-species entanglements that occurred under the apartheid regime. Nadine Gordimer judged this collection at the time as "the first sustained African voice in the English poetry of this country for at least twenty years" (dust jacket). In her introduction, Gordimer acknowledges Mtshali's depictions of the "rural past" but she celebrates him as "pre-eminently [...] the poet of the black Johannesburger" (vii) who "makes-by-naming areas of experience that, for fellow blacks, will provide a shock of recognition, and for whites, a revelation of a world they live in and never know" (v). Embodied dogs inhabit a number of these poems dialogically-serving as markers of privilege in the white suburbs, as cowardly witnesses to police brutality in the townships or as ghoulish scavengers on a rubbish dump.

"The Master of the House" deals very explicitly with the experience of a selflabelled "faceless man" who inhabits the backyard of a white home at night. The poem is addressed to the eponymous "master" as an ironic "confession." The domestic worker, Lizzie, the speaker's lover, feeds him from the master's table, so laden "it huffs like a horse / drawing a coal cart" (55).

The speaker triumphs to some extent in his clandestine eating as each night he "run[s] the gauntlet / wrestle[s] with your mastiff, Caesar, / for the bone pregnant with meat / and wash[es] it down with Pussy's milk" (55).

Both dog and cat as recipients of the bounty of the master's table metonymise the apparent legitimacy and practices of white privilege, a legitimacy which the unnamed speaker undermines in his stealth and his theft of food from the animals. The dog, Caesar, as well as the unnamed cat, exist in this poem not only to be duped by the speaker but also to draw attention to his disempowered position

Tydskrif vir Letterkunde 55.3 (2018) 
as a hungry thief of the food of animals. The aptly named mastiff echoes Mtshali's "Ride Upon the Death Chariot" in which "Caesar's empire" condemns three "vagrants" to death for the travesty of lacking correct identity papers.

In "The Master of the House" the speaker, similarly, has been deprived of his identity and is at the mercy of apartheid practices in the domestic quotidian. Due to "the synergistic taxonomies of race and species" (Kim 18) any entanglements between human speaker and the master's animals are negative-framed within racialised constructions as well as by the social actuality. The speaker is reduced to animality, dehumanised by being compelled to become a "nocturnal animal" who "steals through the fenced lair" so that he can "meet [his] mate" (55). Ironically, the master's house becomes the preserve of an animal too, a "lair", as though the inequities of racist legislation and resultant lifeways reduce both perpetrator and victim/survivor to animality. Ultimately the speaker becomes prey, having to "flee" at dawn before the master of the house, depicted as a hunter aided by his "hounds", is able to "run [him] to ground" (55).

Another poem by Mtshali, "My Shadow, Courage," has a dog figured as embodied as well as metonymic of the vulnerabilities of the human body. The poem opens with the speaker praising his faithful fox-terrier who seems more guardian than pet as his main purpose in life is a protective one:

it snarls and snaps at all gremlins [...]

it stops to sniff, sneeze and piss on a telegraph pole,

and leave a message for every potential follower,

"I passed here; follow if you dare" (59)

The identity of the "gremlins" is not initially clear but the dog seems bravely agentive in the message he leaves for "every potential follower" who could be either canine or human; if the latter, then "follower" surely suggests surveillance by the secret police. A knock on his door during the night elicits the speaker's embodied reaction, which could indicate that, like the "faceless man" in the previous poem, he has been degraded by his own embodiment. The knock "deflate[d] [his] balls" as well as affecting his "hair roots" which then "r[a]n tip-toed in circles on [his] head" (59). Instead of protecting the speaker, Courage "deserted" him retreating to a "ragged bed of fleas" so that the "nakedness" of the speaker was "exposed" and he "shivered for the snake suit" which he had "shed in the grass" (59). This "snake suit" already dispensed with points to a lost camouflage or even a relinquished bravery of a once-deadly reptile.

When the visit by the security police is figured through the speaker's terrified response the reader's sympathy is indubitably elicited, but in the next stanza the poem loses clarity (for this reader at least). The "laughing lice / giggling like benzine drunk urchins / evicted from my bountiful pantry of poems" (59) are mystifying. Not until the final stanza are we back in the narrative of the visit by 
Canine embodiment in South African lyric poetry

the police when the speaker's hand "groped for the doorknob of daybreak / and the morning mist smacked my face awake" (59).

The alliteration and the imagery are startling, with the pollutive mist itself part of the endemic violence that black South Africans experienced during apartheid. ("An Abandoned Bundle" discussed below confirms that the mist is not a natural phenomenon). The poem ends:

There I was. Shadowless there I was.

Empty, like a hulk

waiting for a demolition squad.

O! Courage have you forsaken me forever? (59)

Dialogic possibilities with the dog have not materialised. Without his canine shadow, the speaker is doomed, in anticipation of "demolition," sinisterly by a whole "squad", as though he is a machine or a building. The final line seems to be an invocation both to the missing dog called Courage and to the speaker's lack of courage, yet the once-protective dog has already deserted the speaker and, in doing so, loses his relevance. Naming a dog Courage is heavy-handed, the metaphor too weighty for the fox-terrier to survive. As in "The Master of the House" the dog is figured negatively. In the former poem the dog is an antagonist, in the latter a Judas, both located adversarially within racially politicised situations.

The dogs in "An Abandoned Bundle," are also adversarial to humans-as gothic inhabitants of a dysfunctional, apocalyptic environment. "An Abandoned Bundle," which Gordimer regards as "one of the most shocking poems ever written" (viii), opens in White City Jabavu. A "thick yellow" pollutive combination of mist and domestically generated smoke (in the absence of electricity) resembles "pus" which "oozes" as if "from a giant sore" (60). Apartheid exclusions led not only to deaths at the hands of the security police but to health hazards for township inhabitants, and to lives cut short in infancy. The speaker passes a heap of rubbish where he sees that "scavenging dogs / draped in red bandanas of blood / fought fiercely / for a squirming bundle" (60).

The dogs are primordial beasts, the blood staining their faces almost jauntily displayed (in the "red bandanas") as they turn savagely on each other. The horror, as the next stanza shows, is that this "bundle" which had "squirmed" in agony was now a "mutilated corpse" of "an infant dumped on a rubbish heap" (60). When the speaker threw a brick at them, the dogs "bared fangs" in resentment, then "flicked velvet tongues of scarlet" before they "scurried away" (60). The vivid almost sensuous image of "velvet tongues of scarlet" compounds the hideous provenance of the dogs with whom the only dialogue is one of violence and horror. All that the speaker can do, ineffectually, is address the child:

"Oh! Baby in the Manger

54 sleep well

on human dung." (60)

Tydskrif vir Letterkunde 55.3 (2018) 
In the face of this unspeakable tragedy the only recourse, Mtshali seems to say, is to Biblical myth. The child is Christlike in the sacrifice of his/her life-a premature death, surely, to be laid at the door of the apartheid regime and the resultant landscape of pollution and squalor. Mtshali, however, has the speaker turn on the mother, foreclosing the taxonomic connections between gender and race, as the poem treats her with cutting irony and without compassion. The mother

had melted into the rays of the rising sun,

her face glittering with innocence

her heart as pure as untrampled dew (60)

The contaminated urban environment with its mist which "smothered our little houses / like fish caught in a net" (60) points to a traumatising context of disease and choicelessness which could account for the mother's actions, yet Mtshali depicts her as psychopathically without feeling as she is held solely responsible for the death of the infant. The dogs, too, are irredeemable, creatures inhabiting a dystopia who have been drawn back into the primitive. In "An Abandoned Bundle", with the mother's body abjected as well as those of the dogs, a parallel between them is surely implied. Both are murderers without conscience and stained literally (in the case of the dogs) with the blood of a newly born baby. Both are to be reviled as outsiders beyond civility.

\section{Reading convivialities}

Given the sea-change in the last two decades or more in relation to animal ethics (Jacques Derrida, Cary Wolfe, Donna Haraway, for example) and the widespread scientific recognition of their subjectivities (Marc Bekoff, Vinciane Despret, Jonathan Balcombe, for example) one anticipates that the figuring of dogs will be more expansive in South African poetry. If Pick's notion of creatureliness foregrounds common vulnerabilities of humans and animals, Ralph R. Acampora's theory of symphysis in Corporal Compassion: Animal Ethics and the Philosophy of Body (2006) stresses the conviviality of human-animal embodied connections. Symphysis, he explains, is a neologism for a concept which is different from sympathy and which emphasises corporeality. For Acampora "cross-species compassion is mediated by somatic experiences" (23), as the poems in this section illustrate.

So many of recent South African dog poems are elegiac that they almost constitute a genre, one that is both universalised in its recognition of impermanence and particularised in its acknowledgement of a specific relationship with a beloved dog. None of them deserves Randy Malamud's criticism in Poetic Animals and Animal Souls (2003) that "[m] ost poetry about animals induces a brief, simple, and predominantly anthropocentric moment of contemplation" (27). Instead, Malamud's poetic ideal of a "more rigorous consideration of animals" 
Canine embodiment in South African lyric poetry

(27) is recurrent. Notable also in all these poems is their lack of sentimentality, that excess of emotion which would favour the speaker's response rather than the dog's corporeal trajectory. Kobus Moolman's “To Jessica-planted in the back garden" has the dog's body transmuted into nature in ways that are both embodied and transcendent:

Bones [...] will bud green wings

to stalk the light (18)

The final stanza and the final line on its own beckon the reader to a kind of heaven for Jessica. What signifies is Jessica and her transformation, not the speaker's response to her death:

While dawn to dust

the rain that calls

opens old doorways

of earth

for the sky (18)

The dog's "bodily poeisis" (to borrow a term from Moe 11) has an afterlife in this quiet poem, as two Dalmatians do in Christine Coates' unpublished poem, "Dog Days". The speaker hears the dogs "phantoms now, one on the right, / another on the left" (n. p.) but these ghosts are also tactile beings whom the speaker feels with their "tongues and smiles, ever panting" (n. p.). Margaret Clough's poem "Ghosts" (14) with its conversational light tone contradicts the notion that dogs see ghosts, asserting instead that they smell them. The poem ending, poignantly, as the speaker's small terrier curls up on the worn mat, aware of the smell of Dipstick, the late beagle.

Jenna Mervis' "Good Boy" (10-1), dedicated and addressed to Oscar, is a compassionate, fluidly intersubjective figuring of woman and dog. The poem begins:

We climb quietly

into the night

padding the hot $\operatorname{tar}(10)$

Oscar's "bodying forth" (to use Costello's term) constitutes this poem with the human speaker following after: he is aged, moving "with difficulty"; his "cricket click nails / syncopating the effort" (10). The speaker, dog-like, is hyper aware on a stroll of their "scent intrusion" which sets off neighbourhood dogs "into barking and braying" as she too delights in smells, of the sea on her tongue. Poignantly she questions the old dog about his memory of how they ran "as waves transformed the dunes / with plankton light" (10).

In the present moment, in their trans-species embodied community, they now "shuffle together". That both are lacking in vibrancy renders them metonymic of each other's lives, the speaker "a parched story-teller", the dog "a veteran" who has

Tydskrif vir Letterkunde 55.3 (2018) 
been over-bred. In the next two stanzas woman and dog deal with Oscar's vulnerabilities in a loving interdependent conversation; the woman kneeling to "wash each foot and leg" (11) sodden with urine recalls biblical practices of the washing of travellers' feet. The phrase "good boy" is transformed here into a phatic loving encouragement of Oscar's attempt to straighten his collapsing body. In the final stanza, which balances the first stanza, Oscar is addressed as he

climb[s] quietly

into the night,

hands holding your face

your paws

your great sagging body. (11)

Such extraordinary attentiveness to the beloved dying dog, his past, his pained immobility and incontinence figures Oscar's embodiment as compassionately central. Mervis does not dramatise a speaker who focuses on her own grief or on her expectations that the dog could function as her personal psychopomp. Even the human hands which hold Oscar seem disembodied, generic and unclaimed by the speaker.

Harry Owen's elegiac poems, like those of Mervis and Moolman, are also dialogues with the dogs themselves. In many poems, Owen doesn't 'become' dog in any dramatic way, but the speaker repeatedly takes on an intersubjective voice which is both human and canine. In "Le Bonheur", for example, a celebration of a languid walk in the Grahamstown Botanical Gardens, human-canine happiness is interchangeable:

It is she, it is he, it is you, it is me,

and we're strolling with it here in Bots,

With this four-legged drunkenness,

following our smiling, tongue-lolling, noses. (85)

The subsequent poem in Owen's collection entitled "Elegy" continues this companionate and compassionate voicing. The poem opens with nature quietly acknowledging a buried dog; Dora may be "cosy in her earth cocoon" but "crickets scribbl[e] their loneliness in air" (86). Yet Dora has not left, entirely: the line "Listen: she's lapping" draws us in, as readers, into an exchange with the speaker and the living dog, the speaker and the ghost dog. Billy, the extant dog, agentive in a number of poems is "Snuffling, just checking. He's grieving too" (86). The poem ends with human and dog mutually supporting each other in their tranquil but grieving acceptance of death as a natural phenomenon:

We pay attention, deep attention,

to the dark.

We hold one another up. (86) 
Any anthropocentric implications of Dora's death are not separated out for the human speaker; instead, Owen imagines the mourning of both human and dog for a beloved companion as a communal dialogue.

Owen's poetry brims with such interconnectedness. A lighter poem, "So Do You" glories in human and nature, dog and nature, human and dog. A fir tree, like "some lost god of the underworld", is sexualised and metonymic of a "life we all lead. No whimpering. No death" (83) - redolent of a Buddhist attitude to impermanence. At the start of the next stanza "Billy leads the way" into a "happy collapse" which the speaker imitates, the line also implying that as a canine, Billy is in the forefront of a spiritual awareness of death without regret. The figuring of Billy in the gardens alongside the weavers and starlings is beautifully delineated as he "shakes the world awake" after his "untroubled rolling". In the final stanza Billy and the other dogs "know [...] without thinking" that the (sexual) delight of rolling on the grass is the "same" for them as for the speaker and the human addressee:

only the joy, the carnality of it here

or anywhere is momentous. (84)

The dogs "know" this in an embodied way "without thinking" (84). The poem ends mischievously:

Truth be told so do I.

Come now, truth be told, so do you. (84)

Humans, in this sequence, follow on after the embodied knowledge of the dogs.

\section{Conclusion}

Dogs and humans are entangled in South African lyric poems, which, rather than being private statements, are dialogic, not only in relation to the animal in the poem but in connection with socio-political discourses. A reading of dog-human relationality which focuses on embodiment reveals the commonalities of human and canine-and how the vulnerabilities they sometimes share, are exacerbated by gendered and racialised inequities. In poetic contiguities with humans, dogs may feature metonymically in a trans-species blurring which still has them as embodied subjects. When poems are elegiac, the dog's bodily poeisis is at the core of the poem, so much so that these poems eschew an anthropocentric, sentimentalised response to death, foregrounding instead compassionately imagined endings for beloved dogs, our familiars. 


\section{Acknowledgements}

I am grateful to the National Research Foundation whose funding made this research possible. Thanks are due to Christine Coates, Michael Cope, Kobus Moolman, Harry Owen and Arthur Wheat for their poetic suggestions.

\section{NOTES}

It would be inappropriate for me to analyse my own poetry. Suffice to say that "Dog Day Afternoon" (Love, Hades and other Animals 51), "Talking to Jasper, in the Garden" and "Talking to Mishka, in the Garden” (A Saving Bannister 45-8) are all elegiac dog poems.

\section{WORKS CITED}

Abrams, M. H. \& Geoffrey Galt Harpham. A Glossary of Literary Terms. 10 ${ }^{\text {th }}$ edition. Wadsworth, 2012.

Acampora, Ralph R. Corporal Compassion: Animal Ethics and Philosophy of Body. U of Pittsburgh P, 2006.

Bristow, Tom. The Anthropocene Lyric: An Affective Geography of Poetry, Person, Place. Palgrave Macmillan, 2015.

Clough, Margaret. McGregor Poetry Festival 2016 Anthology. African Sun Media, 2017.

Coates, Christine. "Dog Days." Unpublished poem.

Coetzee, J. M. The Lives of Animals. The University Center for Human Values Series, edited by Amy Gutmann, 1999.

Cope, Michael. E-mail communication, 10 September 2017.

Gordimer, Nadine. Dust Jacket. Sounds of a Cowhide Drum. Renoster, 1971. Foreword. Sounds of a Cowhide Drum. Renoster, 1971.

Jonker, Ingrid. Black Butterflies: Selected Poems: Ingrid Jonker. Trans. André Brink \& Antjie Krog. Human \& Rousseau, 2007.

"Ontvlugting". Poetry International Web. <www.poetryinternationalweb.net/pi/site/poem/ item/11227>. Accessed 5 Dec. 2017.

Selected Poems: Ingrid Jonker. Trans. Jack Cope \& William Plomer. Jonathan Cape, 1968.

Selected Poems: Ingrid Jonker, Revised and Enlarged. Trans. Jack Cope \& William Plomer. Human \& Rousseau, 1988.

Kim, Claire Jean. Dangerous Crossings: Races, Species, and Nature in a Multicultural Age. Cambridge U P, 2015.

Malamud, Randy. Poetic Animals and Animal Souls. Palgrave, 2003.

Mervis, Jenna. Woman Unfolding. Modjadji, 2011.

Miller, Ruth. Poems, Prose, Plays, edited and introduced by Lionel Abrahams. Carrefour, 1990.

Moe, Aaron M. Zoopoetics: Animals and the Making of Modern Poetry. Lexington, 2014.

Mtshali, Oswald Joseph. Sounds of a Cowhide Drum. Renoster, 1971.

Owen, Harry. The Cull: New and Resurrected Poems. The Poets Printery, 2017.

Pick, Anat. Creaturely Poetics: Animality and Vulnerability in Literature and Film. Columbia U P, 2011.

Scanlon, Mara. "Introduction: Hearing Over." Poetry and Dialogism: Hearing Over. Eds. Mara Scanlon \& Chad Engbers. Palgrave Macmillan, 2014, pp. 1-19.

Tydskrif vir Letterkunde 55.3 (2018) 


\section{Canine embodiment in South African lyric poetry}

Serote, Mongane Wally. "Child of the Song." Poetry International Web. <www.poetryinternationalweb. net/pi/site/poem/item/15599/auto/0//CHILD-OF-THE-SONG>. Accessed 3 Mar. 2018.

Woodward, Wendy. Love, Hades and Other Animals. Protea, 2008.

. A Saving Bannister. Modjadji, 2015. 